JIKAP PGSD: JurnalIImiahIlmuKependidikan

Vol, 4. No,1. Tahun 2020

e-ISSN: 2597-4440 dan p-ISSN: 2597-4424

This work is licensed under a Creative Commons Attribution

4.0 International License

\title{
Pola Kepemimpinan Kepala Sekolah dalam Penguatan Karakter di Sekolah Dasar Kota Sintang Kalimantan Barat
}

\author{
Lusila Parida ${ }^{1}$, Sirilus Sirhi ${ }^{2}$ Daniel Dike ${ }^{3}$ \\ ${ }_{1,2,3}$ STKIP Persada Khatulistiwa Sintang \\ Email: ${ }^{1}$ 301086LP@gmail.com \\ sirilussirhi@gmail.com \\ 3dikedanieltukan@gmail.com
}

\begin{abstract}
Abstrak. Penelitian ini bertujuan mendeskripsikan gambaran mengenai pola kepemimpinan kepala sekolah dalam pembentukan nilai-nilai karakter di Sekolah Dasar. Disain penelitian menggunakan penelitian studi kasus di sekolah rujukan Sekolah Dasar Negeri 07 Sintang, sekolah Islam Madrasah Ibtidaiyah Negeri Sintang, dan Sekolah Dasar Swasta Suluh Harapan Sintang. Pemilihan subyek penelitian menggunakan metode sampling area karena pertimbangan karakteristik khusus sekolah berlatar sekolah rujukan, sekolah islam negeri dan sekolah swasta katolik. Pengumpulan data dilakukan melalui observasi, wawancara mendalam, dan studi dokumen. Pemilihan subyek penelitian menggunakan metode purposive sampling. Jumlah total subyek penelitian sebanyak 33 orang, yang terdiri dari 3 kepala sekolah dan 30 guru. Validitas data dilakukan melalui proses triangulasi. Hasil penelitian menunjukan bahwa ciri pola kepemimpinan dominan pada ketiga sekolah cenderung dominan pada pola instrutional leader. Agar proses pembentukan karakter siswa dapat lebih optimal maka kepala sekolah harus melakukan kombinasi pola kepemimpinannya. Pola kepemimpinan transformatif dan kepemimpinan kultural harus dibudayakan dalam penguatan karakter dengan menginovasi program-program strategis sesuai kondisi dan kemampuan sekolah. Program-program penguatan karakter yang diintegrasikan dalam mata pelajaran dan ekstrakurikule siswa harus mengakomodir enam tahapan piramidal habituasi nilai-nilai karakter.
\end{abstract}

Kata kunci: penguatan, karakter, kepemimpinan, transformatif, cultural.

Abstract. This study aims to describe the image of principal's leadership patterns in
the formation of character values in elementary schools. The research design used a
case study research at the Elementary School 07 Sintang, the Islamic Elementary
School Sintang, and Elementary School Suluh Harapan Sintang. The subjects of the
research used the area sampling method because of consideration of the special
characteristics of the schools with reference schools, state Islamic schools and private
Catholic schools. Data collection is done through observation, in-depth interviews and
document studies. The selection of research subjects using the purposive sampling
method. The subjects of these researches were 33 people consisting of three principals
and 30 teachers. Data validity is done through the triangulation process. The results
showed that the dominant leadership patterns in the three schools tended to be
dominant in the instructional leader pattern. For the process of forming the students'
character to be more optimized, the principal must do a combination of leadership
patterns. Transformative leadership patterns and cultural leadership must be cultivated 
in strengthening character by innovating strategic programs according to the conditions and abilities of the school. The character strengthening programs that are integrated into students' subjects and extracurricular for students must accommodate the six stages of the pyramid of habituation of character values.

Keywords: strengthening, character, transformative, cultural, leadership

\section{PENDAHULUAN}

Problem-problem sosial terkait karakter siswa dalam bidang pendidikan pada lima tahun terakhir di kota Sintang mendapat perhatian cukup serius dari dinas pendidikan dan pemerintah kabupaten Sintang. Mengingat menguatnya kasus kenakalan remaja seperti tindakan asusila, kasus pembunuhan terhadap kepala sekolah oleh orangtua siswa, pencurian, kasus narkoba, serta meningkatnya penderita AIDS dikalangan muda menghadirkan kekuatiran tersendiri di kalangan masyarakat dan pemerintah (Prayogi, 2019). Kondisi tersebut mendorong adanya pemikiran tentang pentingnya peraturan daerah untuk mengatur sistem belajar dan jam belajar agar hal-hal negatif dapat diminimalisir. Hasil survey tahun 2018 dilakukan di sekolah-sekolah kota Sintang ditemukan fenomena kuat adanya perilaku intoleran, indisipliner, masih rendahnya disiplin waktu untuk belajar, adanya kejadian saling ejek (bully) atau perundungan siswa lewat media sosial facebook dengan menguploud vidio tindakan perundungan (Pujianto, 2019). Kasus lain yang sempat memanas adalah saling mengejek dan menghina simbol-simbol agama yang membangkitkan isu SARA dan tindakan persekusi terhadap etnis atau agama tertentu sehingga berproses sampai ke wilayah hukum (Wahidin, 2019).

Dalam pergaulan sosial siswa menguat kecenderungan anak-anak mulai memililih dan membatas pergaulan dengan teman seiman dan mulai menutup diri terhadap anak-anak lain yang berbeda keyakinan. Pembelahan dalam politik ikut berdampak secara sosial sampai di level pergaulan anak-anak di tengah masyarakat sehingga memberi kesan kuat bahwa sikap intoleransi dan kebencian terhadap kelompok lain adalah sesuatu yang secara langsung atau tidak langsung diajarkan kepada anak-anak.

Penguatan pendidikan karakter merupakan salah satu upaya yang dilakukan pemerintah dalam mewujudkan tujuan pendidikan nasional. Implementasi penanaman nilai-nilai karakter harus dilakukan oleh orang tua, guru dan masyarakat dilingkungan (Setiawati \& Nia, 2018).
Pendidikan karakter di sekolah dasar adalah proses membiasakan siswa membangun pemahaman moral (moral knowing), sensivitas moral (moral feeling) dan tindakan moral (moral action) dalam kehidupan mereka sehari-hari. Penemuan dan pemaknaan nilai-nilai moral dikonstruksi dan dibudayakan melalui proses pembiasaan lingkungan dan bukan semata-mata lewat pengajaran di ruang kelas sebagai proses transfer of knowledge. Martin Heidegger menerangkan bahwa belajar adalah membuat segala sesuatu yang kita jawab menjadi hakikat yang selalu menunjukan dirinya sendiri setiap saat, karena apa yang dituntut dari mengajar adalah membiarkannya belajar (Bonnet, 2010). Jadi proses penguatan karakter proses kebudayaan, dimana produk kehidupan sosial dan aktivitas manusia dikembangkan.

Sebagai pemimpin pembelajaran kepala sekolah harus memahami bahwa aspek pikiran dan kognisi dan ingatan siswa adalah sesuatu yang melampaui aspek fisik (extending beyond the skin) sehingga proses belajar dalam penguatan karakter siswa adalah menghidupkan fungsi-fungsi intermental maupun extramental dalam kebudayaan (Ardichvili, 2010). Proses belajar dan pembentukan karakter terjadi ketika apa yang muncul pada niat intermental diinternalisasi siswa dalam proses intersubyektifnya. Artinya, proses karakter dalam diri siswa membutuhkan peran kekuatan lingkungan sosial (social environmet) maupun peran kekuatan batin (inner resources) siswa sendiri, sebab nilai-nilai karakter itu tertanam secara sosial dalam lingkungan budaya tertentu (Elkind and Sweet, 2019). Penanaman nilai karakter di sekolah harus tiba pada kesadaran siswa bahwa ia tahu tujuan belajar dan bagaimana harus belajar (learn how to learn). Jadi nilai tertinggi dari proses belajar adalah kemampuan siswa menjadi dirinya sendiri yang memiliki tangungjawab atas apa yang harus dilakukan, kapan sesuatu itu harus dikerjakan, serta bagaimana cara melakukannya, tanpa memandang apa siswa senang atau tidak dengan apa dikerjakannya (Zamroni, 2014). 


\section{METODE PENELITIAN}

Penelitian ini adalah penelitian kualitatif dengan bentuk case study research, untuk mengkaji fenomena faktual pendidikan dasar terkait program penguatan pendidikan karakter di sekolah (Ary, D., Jacobs, L.C., \& Sorensen, 2010). Data dianalisis dengan menggunakan model interaktif Miles and Huberman untuk mendapatkan konsep holistic tentang peran kepemimpinan kepala sekolah dalam membangun karakter siswa di sekolah dasar. Penelitian ini dibagi dalam tiga tahapan, tahap pertama adalah persiapan. menentukan dan menyusun instrument penelitian. Tahap kedua adalah pelaksanaan penelitian mengacu pada tahapan kualititatif case study research. Tahap ketiga adalah analisis data dan menarik kesimpulan untuk mendeskripsikan pola kepemimpinan kepala sekolah dalam penguatan karakter siswa SD.

Penelitian ini dilaksanakan di Sintang, Kalimantan Barat dengan metode sampling area yakni sebagian populasi yang dianggap mewakili keseluruhan ciri populasi yang dikehendaki atau merepresentasikan ciri populasi sekolah dasar yang ada di kota Sintang. Penelitian ini memilih area dengan karakter strategis yaitu SD Negeri 07 Sintang sebagai sekolah rujukan, SD Madrasah Ibtidaiyah Negeri sebagai sekolah dasar dengan karakteristik Islam, dan SD Suluh Harapan sebagai sekolah swasta dengan karakteristik multicultural (katolik). Penelitian ini secara gradual di laksanakan dari bulan Februari-Agustus 2019.

Subjek dalam penelitian ini adalah kepala sekolah dari ketiga sekolah yang dipilih. Pemilihan subyek penelitian menggunakan metode purposive sampling dengan pertimbangan bahwa subyek yang dipilih atau ditententukan sesuai tujuan riset yang mau dicapai. Atas pertimbangan bertujuan tersebut dipilih 3 orang kepala sekolah dari tiga sekolah, dan 10 guru dari tiap-tiap sekolah sehingga jumlah subyek penelitian berjumlah 33 orang. Kepala sekolah dipilih karena ia berperan dan bertanggungjawab penuh dalam implementasi pendidikan karakter siswa. Objek penelitiannya adalah pola kepemimpinan kepala sekolah dalam implementasi pendidikan karakter di sekolah dasar.

Perolehan data dilakukan dengan wawancara mendalam terhadap kepala sekolah terkait habituasi karakter unggul siswa melalui peran kepemimpinan kepala sekolah dalam membangun karakter siswa berdasarkan perannya sebagai manager, leader dan motivator. Disain case study research (Baxter \& Jack, 2008; Yin, 2009) menggabungkan berbagai data baik dari amatan dan wawancara, dan studi dukumen terkait guru dan kepala sekolah. Pusat amatan adalah kegiatan dan aktivitas kepala sekolah, guru dan siswa terkait penguatan karakter dalam proses pembelajaran di ketiga sekolah baik di sekolah Rujukan SD Negeri 7 Sintang, MIN Sintang dan SD Suluh Harapan.

Analisis data penelitian ini dilakukan secara induktif (interaktif), yaitu penelitian dimulai dari fakta empiris dan melakukan pembentukan data yang telah dikumpulkan dengan analysis interactive model Miles \& Huberman (Iman Gunawan, 2015). Proses analisis data ini terbagi menjadi tiga tahapan penting yaitu melakukan reduksi data, display data dan verikasi/penarikan kesimpulan yang dilakukan secara berulang dan interaktif sampai memastikan seluruh datanya sudah ajek atau valid (Miles \& Huberman, 1994).

\section{HASIL DAN PEMBAHASAN}

Bagian hasil dan pembahasan ini mendeskripsikan bagaimana pola kepemimpinan kepala sekolah dalam penguatan karakter siswa sekolah dasar di tiga sekolah dasar dengan karakteristik yang berbeda. Secara rinci hasil dan kajian aspek-aspek tersebut diuraikan sebagai berikut:

\section{Peran Kepala Sekolah dalam Penguatan Karakter di SDN 7 Sintang}

a. Peran Kepala Sekolah sebagai Manager

Peran Kepala sekolah sebagai manager dalam penguatan nilai-nilai karakter tergambar dari informasi wawancara dan amatan dijumpai data dan fenomena terkait adanya upaya penciptaan managerial yang baik di sekolah. Implementasi lima pilar penting ini melalui peran managerial.

\section{b. Peran Leader}

Peran kepala sekolah sebagai leader dalam penguatan nilai-nilai karakter dilakukan melalui pemberian arahan, pendelegasian dan pemberian keputusan.

\section{c. Peran Motivator}

Peran kepala sekolah sebagai motivator dalam penguatan karakter berdasarkan amatan dan wawancara mampu menciptakan iklim kerja yang baik, menyenangkan dan transparansi serta memberikan penghargaan dan kepercayaan kepada guru. 


\section{Peran Kepala Sekolah dalam Penguatan Karakter Siswa di Sekolah Madrasah Ibtidaiyah Negeri Sintang \\ a. Peran Managerial}

Madrasah Ibtidaiyah Negeri Sintang merupakan sekolah di bawah kementerian agama sehingga kurikulum yang digunakan adalah kurikulum nasional berdasarkan semangat, misi dan nilai-nilai islam. MIN sangat konsen terhadap pembentukan karakter siswa berlandaskan landasan Alqur'an dan Hadist dan tradisi religius islam. Perilaku religius ini tampak dalam sikap-sikap islami yang ditanamkan melalui pembentukan watak, sikap, tindak tanduk, tutur kata, sikap doa, ibadah, sikap hormat kepada guru, orangtua, teman dan sesama. Semua program dan praktik perilaku ini didukung dengan sarana memadai yakni gedung sekolah yang cukup megah serta bangunan Surau dua lantai sebagai pusat kegiatan rohani b. Peran leader

Peran kepala sekolah sebagai leader berdasarkan amatan dan wawancara menghasilkan pola kepemimpinan yang selalu mengarahkan guru maupun karyawan dengan petunjuk teknis dari kepala sekolah terkait dengan penguatan karakter siswa, serta setiap keputusan yang hasil dihasilkan didasarkan pada keputtusan musyawarah.

c. Peran Motivator

Berdasarkan amatan dan wawancara disimpulkan beberapa point penting peran motivator kepala sekolah, diantaranya: memberikan keteladanan sebagai pemimpin untuk menjadi model karakter baik bagi bawahan maupun siswa, melakukan kerjasama dan kolaborasi yang baik antara sesama guru.

\section{Peran Kepemimpinan Kepala Sekolah di SD Suluh Harapan Sintang}

Peran kepemimpinan kepala sekolah di

SD Suluh Harapan memiliki warna kepemimpinan yang khas sesuai dengan nilai-nilai pendidikan katolik. Meskipun tidak eksplisit diberi nama sekolah katolik namum nilai dan visi universalnya dilandasi oleh nilai-nilai pendidikan katolik yang sifatnya terbuka pada semua nilai baik yang ada pada semua agama dan budaya. Hal ini terkondisi oleh visi dan misi pendiri yang berlatar katolik. Kepala sekolah yang mengemban tugas pemimpin minimal memiliki latar belakang dan pemahaman terhadap visi pendidikan katolik yang menegaskan 100\% katolik dan $100 \%$ Indonesia. Secara ringkas dijabarkan tiga peran kepemimpinan kepala sekolah sebagai berikut:

a. Peran Manager

Sekolah ini menjalankan kurikulum pendidikan sesuai kurikulum nasional, namun sebagai sekolah swasta yang memiliki otonomi tentu memiliki visi dan misi dalam mendukung program pemerintah untuk mencerdaskan anak bangsa. Sebagai sekolah katolik dalam implementasinya dibidang akademik maupun non akademik mengakomodir semua agama dari siswa dan guru yang ada di sekolah seperti, katolik, protestan, islam dan budha, konghucu. Kepala sekolah sebagai manager memiliki program program sekolah untuk penguatan nilai-nilai karakter.

b. Peran Leader

Peran Kepala Sekolah sebagai leader dalam penguatan nilai-nilai karakter berdasarkan wawancara dan amatan menghasilkan pola kepemimpinan berupa adanya pembagian tugas dan tanggung kepada guru dalam menjalankan tugas baik dalam pembelajaran maupun diluar akdemik, melakukan pengarahan secara langsung, berkolaborasi serta bertanggungjawab dalam menjalankan tugas yang diberikan.

c. Peran kepala sekolah sebagai motivator

Peran Kepala Sekolah sebagai motivator dalam penguatan nilai-nilai karakter berdasarkan wawancara dan amatan menghasilkan pola kepemimpinan berupa memberikan contoh kedisiplinan kepada bawahan, memberikan ketegasan kepada guru yang dinilai kurang disiplin, melakukan upaya pendekatan persuasif berupa pendekatan parenting dalam proses belajar siswa dan adanya keteladanan yang diperankan kepada sekolah dalam ucapan pakaian,, pola asuh dan perbuatan.

Usaha-usaha yang dilakukan untuk penguatan karakter di tiga sekolah umumnya terintegrasi dalam kegiatan belajar dan melalui kegiatan rutin sekolah. Hal ini terlihat dari adanya kesamaan program dan kegiatan sekolah sebagai upaya nyata mewujudkan sekolah berkarakter. Berdasarkan amatan dan wawancara yang dilakukan di SD Negeri 7 Sintang, SD Suluh Harapan dan Madrasah Ibtidaiyah Negeri Sintang menggambarkan adanya upaya penguatan karakter melalui penyususan Visi, Misi dan Tujuan sekolah yang berbasis nilai-nilai karakter. Di ketiga sekolah pembelajaran diintegrasi dengan penguatan yang didukung oleh nama besar sekolah dengan kategori sekolah Adiwiyata (SDN 07), sekolah berbasis karakter religious (MIN), sekolah multikultural (SD Suluh Harapan). 
Implementasi kebijakan penguatan karakter dilakukan melalui analisis kondisi sekolah, merencanakan supervisi sebagai upaya peningkatan profesionalisme guru serta membuat struktur organisasi sekolah dengan bagan konsep tulisan yang disosialisasi lewat papan flocat diruangan guru dan kepala sekolah. Pembenahan administrasi dan modernisasi data melalui bank data sekolah program dapodak merupakan bagian dari upaya meningkatkan dan mempertahankan status akreditas sekolah dengan kategori unggul. Implementasi kebijakan pendidikan karakter mulai difokus lebih dahulu pada upaya memperlancar kegiatan belajar siswa sehingga fokus kepala sekolah terarah pada penyusunan data guru, bank data siswa, grafik keadaan siswa, membuat buku tamu, membuat buku mutasi, jadwal rapat sekolah dan rapat komite sekolah. Kegiatan yang spesifik ditentukan oleh kekhususan masing-masing sekolah. Misalnya, Madrasah memiliki rencana melaksanakan program keagamaan yang berpedoman pada haditz dan Alquaran dan program habituasi nilai-nilai budaya islam. Program rutin yang dilakukan sekolah atau guru adalah menyiapkan kelengkapan Silabus, RPP, Bahan Ajar, sarana ruang kelas, lapangan olahraga, kantin, parkir, taman terbuka hijau, surau yang difungsikan sebagai tempat ibadah dan aula.Pembelajaran berjalan normal setiap sekolah dan belum terlihat adanya program khusus yang menampilkan adanya sosialisasi yang masif terkait penguatan karakter.

\section{Pola Kepemimpinan Kepala Sekolah dalam Penguatan Karakter}

Perbedaan pola kepemimpinan ditentukan oleh kebijakan program, eksekusi program dan evaluasi pencapaian program serta norma-norma dan kultur organisasi sekolah. Pola kepemimpinan dipandang sebagai satu persyaratan kunci kesuksesan, prestasi, dan pencapaian tujuan organisasi (Yukl, 2002). Dari kacamata tersebut dapat dilihat bahwa pola kepemimpinan terkait penguatan pendidikan karakter pada ketiga sekolah sama-sama lebih difokus pada kepemimpinan pembelajaran (instructional leadership). Hal ini terlihat dari titik penekanan pada target capaian kurikulum dan kegiatan belajar setiap hari di sekolah. Program penguatan karakter akhirnya lebih diorientasikan pada program kegiatan rutin sekolah. Ketiga kepala sekolah belum memiliki program strategis penguatan karakter yang khas (khusus) sesuai kondisi, kebutuhan dan keunggulan sekolah. Jadi program strategis yang dimiliki oleh kepala sekolah adalah "program intergrasi nilai karakter melalui mata pelajaran sesuai arahan kementrian pendidikan. Dengan demikian program pendidikan karakter masih terlihat sebagai program rutin pembelajaran setiap mata pelajaran yang diajar guru di setiap sekolah. Ada indikasi kuat bahwa semua sekolah ingin maju dengan hasil yang baik, dengan prestasi yang banyak diraih dalam berbagai iven O2SN di tingkat kabupaten, provinsi dan nasional.

Dinamika pendekatan scientific dalam kurikulum 2013 belum banyak terlihat dalam implementasinya di kelas meskipun rencana pembelajaran sudah menyertakan nilai-nilai karakter. Belajar masih dominan di ruang kelas dengan pola konvensiona, belum banyak aktivitas observasi, menanya, membuat eksperimen, membangun asosiasi dan penalaran siswa, membiasakan tindakan komunikasi dan kolaborasi diantara guru. Cukup kuat diarasakan fenomena siswa diberi banyak pekerjaan rumah, les-les tambahan di rumah guru untuk memenuhi capaian nilai kognitif siswa. Ini fenomena umum yang cukup banyak ditemukan di sebagian besar sekolah dasar. Materi kurikuluim yang banyak dan guru sendiri belum mahir dalam mengelola pembelajaran tematik dengan pendekatan scientific, membuat proses kreativitas, inovasi dan pengembangan kemampuan berpikir kritis (high other thingking skill) masih cukup lemah di sekolah-sekolah. Terkait probelematika ii kepala sekolah belum memiliki kebijakan dan program strategis khusus yang dirancang untuk penguatan pendidikan karakter di sekolah berbasis kelas, berbasis sekolah dan berbasis masyarakat sebagai bagian integral dari proses pendalaman dan perluasan bidang penguatan karakter (Tim Penyusun, 2017b). Umumnya penekanan program terfokus pada unsur aspek disiplin waktu, kebersihan, kerapihan berpakaian dan kondisi lingkungan sekolah dengan tanaman hias yang mendapat perhatian dan prioritas lebih ketika sekolah mempersiapkan visitasi akreditasi sekolah. A

Ada upaya inovasi program seperti di SDN 07 Sintang melalui program operasi semut yang mewajibkan seluruh siswa dan guru memungut dan membersihkan sampah di sekitar sekolah, ruang kelas sebelum memulai dan mengakhiri pelajaran. Target yang ingin dicapai adalah menjaga dan merawat kebersihan lingkungan sekolah dengan nilai karakter yang ditanamkan adalah tanggung jawab dan 
kemandirian. Di setiap dinding sekolah, di area depan di pampang 18 nilai karakter sebagai bagian dari sosialisasi membangun ingatan siswa terkait nilai-nilai karakter namun tidak semua siswa memberi perhatian yang serius terhadap semua nilai yang tercatat di papan flocat dari 5 bidang prioritas yang dikembangkan yakni, religius, nasionalis, integritas, gotong royong dan mandiri. Penguatan nilai karakter terlihat juga dari fenomena di ruang-ruang kelas, di teras, di gang-gang sekolah terpampang tulisan atau qout, kata-kata bijak yang bertujuan memotivasi siswa untuk hal-hal yang baik atau nilai kebajikan. Tulisan-tulisan tersebut mencerminkan upaya sekolah memperkenalkan dan mensosialisasikan nilai karakter agar siswa tahu, paham dan bisa menjalankan beberapa keunggulan yang dimiliki sekolah. Keunggulan sekolah seperti sekolah Adi Wiyata membangun kesadaran publik sekolah bahwa kebersihan menjadi bagian penting dari kehidupan pribadi dan komunal.

Hal yang sama juga terlihat di SD Suluh Harapan, ada qout dan kata-kata motivasi ditempel, digantung di dinding ruang kelas. Tulisan dan qout semacam ini dihrapkan memberi informasi pengetahuan dan ingatan siswa dan para pengunjung. SD Suluh Harapan terarah untuk mencapai enam nilai yang ia yakini diperlukan untuk pendidikan abad 21 yaitu: 1) sehat, 2) mandiri, 3) tekun, 4) berpikir terbuka, 5) memiliki jiwa kepemimpinan, 6) bersyukur. Dengan demikian kebijakan sekolahnya menekankan pentingnya parenting. Parenting difokuskan pada hal-hal sederhana seperti penanaman nilai sopan santun, kehalusan dalam bertutur kata dan menyapa orang lain yang seusia dan yang lebih tua.

Intervensi kebijakan pembelajaran dan karakter di SD Suluh Harapan menekankan pada "Nilai-nilai seperti tubuh harus selalu sehat, mandiri, tekun, berpikir terbuka, memiliki jiwa kepemimpinan." Nilai-nilai ini selalu ditanamkan dalam diri siswa dalam setiap pembelajaran di sekolah oleh guru. SD Suluh Harapan membudayakan proses dan kegiatan belajaran secara menyenangkan dengan tetap fokus pada penguatan nilai keagamaan, moral dan etika, melatih kebiasaan yang baik bagi guru, karyawan dan peserta didik. Bahasa dan perilaku yang baik dan lembut harus pertama-tama ditunjukan oleh guru. Karena itu disekolah ini tidak ada toleransi bagi guru yang melakukan kekerasan verbal maupun fisik terhadap siswa. Siswa juga memperkuat literasi sastra dan bahasa melalui pengajaran bahasa nasional maupun internasional seperti bahasa Inggris dan Mandarin diajarkan di SD Suluh Harapan.

SD Suluh Harapan sebagai sekolah swasta yang didirikan oleh tokoh-tokoh Katolik secara tidak langsung mengembangkan nilai-nilai kristiani yang sejalan dengan budaya multikultural yang tetap berpedoman pada konsep pendidikan Katolik seperti Gravissimum Educationis (GE). Sistem ini tidak hanya menekankan aspek akademik tetapi kemanusiaan universal yaitu "...setiap anak memperoleh pengetahuan yang secara berangsur-angsur diperoleh tentang dunia, kehidupan dan manusia yang disinari oleh terang iman." Dasar filosofis persekolahan katolik umumya terkait visi ideal tentang manusia. Kemampuan ini dicapai atau yang wajib dimiliki siswa ketika menempuh suatu jenjang pendidikan tertentu termasuk sejak pendidikan dasar terkait karakter (Sarkimin, 2017). Inti dari pendekatan parenting yang dikembangkan kepala sekolah dalam strategi penguatan karakter di SD Suluh Harapan terarah pada pembentukan kepribadian dan kemanusiaan utuh dari generasi muda yang tumbuh dalam kasih Allah yang dilengkapi dengan akal budi dan kepribadian yang baik sehingga mampu mempertanggung jawabkan seluruh tindakan dan pendiriannya.

Penguatan karakter di Madrasah Ibtidaiyah Negeri Sintang lebih dominan pada dimensi religius karena sekolah ini berlatar agama islam dan berada di bawah kementrian agama. Karakter dan program karakter yang diupayakan di dalam proses belajar adalah penanaman nilai-nilai dan budaya islami baik dari tata krama sopan santun, cara berpakaian semuanya disesuaikan dengan nilai-nilai dan tradisi islam. Hal ini terlihat mulai dari bangunan fisik sekolah, sarana pra sarana, penggunaan hijab maupun aturan lainnya sangat mencerminkan karakteristik sekolah yang khas islam. Sekolah ini homogen karena semua guru dan siswanya beragama muslim. Disatu sisi kepemimpinan dalam semua program menjadi lebih mudah karana satu kebijakan menjangkau semua dalam satu kegiatan bersama seperti berdoa, sholat berjemaah, kebijakan infaq, atau membuat acara khusus keagamaan seperti perayaan-perayaan keagamaan sangat mudah dikondisikan dan dikordinir. Tekanan peran kepala sekolah adalah berupaya menciptakan kehidupan sekolah yang sehat, agamis, memiliki moralitas dan etika islam yang kuat. Lingkungan dan kondisi sekolah yang homogen sangat 
membantu peningkatan kinerja sekolah dalam mendukung terciptanya kehidupan religius yang lebih baik di sekolah (Asmendri, 2014). Hal ini tergambar jelas dalam surat Ali Imran, 3:103, "Dan berpeganglah kamu semuanya kepada tali (agama) Allah, dan janganlah kamu bercerai berai." Juga sesuai firman Allah dalam surat As Shaff (61:4) dinyatakan, "sesungghnya Allah menyukai orang yang berperan di jalan-Nya dalam barisan yang teratur, seakan-akan mereka seperti satu bangunan yang tersusun kokoh" (Zamroni, 2014). Modal sosial religius inilah menjadi kekuatan kepala sekolah dalam menggerakan dan merancang program strategis berbasis nilai-nilai unggul islam dalam penguatan, perluasan dan pendalaman pendidikan karakter di level kelas, sekolah dan masyarakat.

\section{Strategi dalam Penguatan Pendidikan Karakter}

Kemampuan kepala sekolah diukur dari keterampilannya mengartikulasi visinya disetiap kesempatan serta kapasitasnya mempengaruhi guru, staf, siswa, orangtua dan semua pemangku kepentingan lainnya (Chang, 2004; Goverment, 2018). Agar kepemimpinan menjadi efektif, kepemimpinan harus dibangun di atas dasar yang kuat yakni adanya visi dan misi yang jelas untuk masa depan, ada strategi spesifik, dan adanya budaya sukses (Charanjit S. Rihal, 2017). Umumnya ketiga sekolah dmasih berkutat pada semua peran dan program rutin sekolah dan program rutin, seperti upacara bendera setiap hari senin, adanya piket kelas, disiplin berbaris masuk kelas, doa bersama sebelum masuk kelas atau sebelum memulai pembelajaran, sholat berjemaah, kegiatan rohani setiap Jumat bagi yang non muslim, ketemu guru memberi salam dan cium tangan. Atau program spontan terkait mengumpulkan sumbangan untuk korban bencana, kematian atau kedukaan yang menimpa siswa, guru atau orangtua siswa dan guru. Beberapa kegiatan di luar jam sekolah seperti ekstrakurikuler dan pramuka wajib hanya. Strategi penguatan yang transformatif belum dimiliki sekolah. Strategi kebijakan untuk mengotimalkan integrasi nilai karakter dalam mata pelajaran dan kegiatan rutin melalui management pengelolaan kinerja kepala sekolah untuk penguatan karakter.

Hal ini penting untuk mendukung dan meningkatkan kapasitas dan skill kepala sekolah untuk mendisaian program untuk pendidikan karakter yang dijangkau sekolah dan terukur dalam evaluasi pencapaiannya. Dalam kaitan dengan peran leader, manager, motivator kepala sekolah dapat menginovasi dan memperkuat strategi penguatan karakter melaui rancangan sederhana untuk memimpin, menata kegiatan guru dan siswa, serta memberi motivasi kepada guru untuk mengembangkan kegiatan secara inovatif. Umumnya kepala sekolah saat ini sudah tidak diberi beban mengajar sehingga sangat dimungkinkan dirinya lebih fokus untuk memikirkan program terobosan dan penataan management berbasis sekolah untuk merealisasi penguatan karakter. Hal ini penting agar kepala sekolah tidak terjebak pada habituasi karakter yang sifatnya rutinitas saja.

Umumnya kepala sekolah sudah unggul dalam kepemimpinan pembelarajan (instructional leadership) tetapi belum banyak mengembangkan kemampuan kepemimpinan transformatif (trasformatif leadership). Model kepemimpinan tranformatif harus lebih dibudayakan di sekolah terkait penguatan karakter. Pola ini akan lebih mendorong kepuasan dan keyakinan siswa dan guru, guru merasa tidak tertekan dan memberi perhatian pada kemajuan siswa (academic excelent) serta memberi keyakinan kepala sekolah terhadap kinerjanya sendiri. Hasil penelitian yang dilakukan di sekolah-sekolah kecamatan Purwakarta ditemukan bahwa kepemimpinan yang lebih tranformatif memberi dampak yang lebih baik terhadap kemajuan sekolah (Yuningsih \& Herawan, 2015). Demikian juga perbaikan sistem dan aspek layanan mutu manajemen sekolah akan memberi dampak positif bagi perbaikan kinerja guru dan layanan yang bermanfaat bagi siswa (Dike, Daniel, \& Parida, 2016, 2019; Ozkan, 2015). Kepemimpinan transformasional menekankan adanya pergeserean dari dimensi kepemimpinan menuju profesionalisme, karena profesionalisme lebih menekankan kompetensi dari pada sekedar keterampilan memimpin (Lynch, 2015).

Dalam mempercepat peningkatan hasil dan dampak penguatan nilai-nilai karakter maka kepala sekolah perlu juga mengembankan kepemimpinan berbasis budaya (cultural leadership) karena karakter tidak lepas dari konteks sosial dan budaya setempat, budaya sekolah (Carjuzaa, 2012; John Keedy, 2002). Cultural leadership menekankan pemahaman dan kompetensi terkait nilai-nilai kepercayaan dan identitas sosial kultural siswa dan guru. Menurut Nononka dapat ditempuh melalui empat strategi yakni sosialisasi, eksternalisasi, 
kombinasi, dan internalisasi. Langkah sosialisasi bisa ditempuh melalui berempati dengan orang lain dan lingkungannya melalui pertukaran subyektif antar individu di ruang-ruang kelas atau lingkungan sekolah. Tujuanya, membantu guru dan siswa memperoleh dan meningkatkan pengetahuan tentang budaya dan meminimalisir adanya prasangka yang terbentuk sebelumnya. Strategi internalisasi dilakukan dengan menerima dan meperdalam nilai-nilai baik yang dibentuk dan dihadirkan dari interaksi akulturasi budaya yang terjadi di sekolah. Strategi kombinasi diupayakan dengan mengkombinasikan berbagai pendekatan strategi kepemimpinan dan management sehingga ia tidak terpola pada satu model pendekatan saja dalam penguatan karakter (Nonoka, 2005). Keempat aspek ini dikembangkan melalui pembiasaan dan keteladanan kepala sekolah, guru, orangtua dan lingkungan terkait 18 nilai karakter yang ditopang oleh lima program prioritas melalui pola piramidal dari tahap mengetahui, memahami, membiasakan, meyakini, melakukan dan mempertahankan nilai-nilai karakter sebagai way of life. atau cara hidup sebagaimana terlihat pada gambar berikut ini:

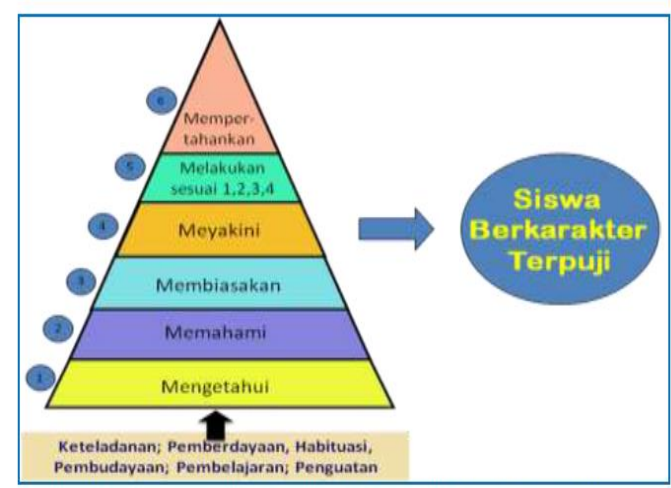

Gambar 1. Proses Pembentukan dan habitasi nilai karakter siswa (Suyanto, 2014)

\section{SIMPULAN DAN SARAN}

Dari uraian yang dipaparkan dalam hasil dan pembahasan berikut ini beberapa kesimpulan dan saran untuk peningkatan kapasitas kepemimpinan kepala sekolah dalam penguatan pendidikan karakter di sekolah dasar.

a. Implementasi pendidikan karakter baik pada sekolah Negeri, Madrasah dan sekolah Swasta masih terfokus pada integrasi nilai karakter melalui mata pelajaran dan belum ada program-program inovatif kepala sekolah untuk perluasan dan pendalaman karakter di sekolah karena kepemimpinan kepala sekolah dominan pada pola kepemimpinan pembelajaran (instructional leadership).

b. Beberapa program terobosan yang dilakukan lebih terkait dengan upaya memberdayakan dan membudayakan kebiasaan baik dengan nilai-nilai karakter yang sudah dilakukan di sekolah seperti upaya menjaga kebersihan ruang kelas, lingkungan sekitar, menyapu kelas dan halaman, memungut sampah dan menyiram bunga, tugas piket rutin oleh siswa dan guru. Hal-hal ini perlu dilakukan dengan melampaui hal-hal yang rutin dari sisi kebijakan.

c. Hasil penguatan pendidikan karakter yang dihadirkan di sekolah melalui intervensi pembelajaran belum diperluas secara optimal dengan metode dan pendekatan pembelajaran kontekstual dan inovatif, misalnya melalui pendekatan inquiri learning, problem solving, dan pendekatan dan penilaian project dan product dalam pembelajaran. Pendekatan scientif dalam implementasi K.13 belum membudaya sebagai budaya belajar untuk membangun keterampilan belajar (learn how learn) siswa sehingga nilai karakter bukan sebatas penanaman informasi pengetahuan semata tetapi membudayakan siswa sendiri menemukan nilai dan makna lewat aktivitas di dalam dan di luar sekolah.

Untuk meningkatkan keberhasilan penguatan pendidikan karakter di sekolah maka kepala sekolah perlu mengembangkan pola kepemimpinan transformatif leadership dan cultural leadership sehingga memberi ruang inovasi program-program penguatan karakter misalnya dengan membuat tabel acuan program pendidikan karakter yang bisa dirancang secara kolaboratif dan team work bersama guru dengan melibatkan institusi lain di luar sekolah. Upaya ini perlu dilakukan untuk memperkuat implementasi K.13 yang berbasis karakter, literasi, 4C (communication, colaboration, creativity, critical thinking) dan HOTS (high order thingking skills).

\section{DAFTAR RUJUKAN}

Ardichvili, A. 2010. Lev semyonovich vigotsky. In J. A. Palmer (Ed.), 50 Pemkir paling berpengaruh terhadap dunia pendidikan moderen: Biografi, dedikasi, dan kontribusinya (Terjemahan, pp. 62-68). Yogyakarta: Penerbit Laksana. Retrieved from www.divapress-online.com

Ary, D., Jacobs, L.C., \& Sorensen, C. 2010. Introduction to research in education 
(eighth). Belmont: wadsworth Cengage Learning.

Asmendri. 2014. The roles of school principal in the implementation of character education at boarding school. Al-Ta'lim Journal, 21(2), 104-111. https://doi.org/ http://dx.doi.org/10.15548/jt.v21i2.87

Carjuzaa, J. 2012. The Positive Impact of Culturally Responsive Pedagogy: Montana's Indian Education for All The Montana Context Indian Education for All: Old Promise, New Movement Moving in a Positive Direction Educators' Personal Reflections on Professional Development Pr. International Journal of Multicultural Education, 14 (3), 1-17.

Chang, L. 2004. The role of classroom norms in contextualizing the relations of children's social behaviors to peer acceptance. Developmental Psychology, 40(5), 691-702. https://doi.org/10.1037 /0012-1649.40.5.691

Charanjit S. Rihal, M. 2017. The importance of leadership to organizational success. NEJM Catalyst: Department of Cardiovascular Medicine. Retrieved from. https://catalyst.nejm.org/importanc e-leadership-skills-organizational-succes s/

David H. Elkind and Freddy Sweet. 2019. How to do character education. Los Angeles. Retrieved from https://www.good character.com/how-to-articles/how-to-do -character-education/

Dike, Daniel, \& Parida, L. 2016. Persepsi dan konsepsi mutu pendidikan sekolah dasar. Pendidikan Dasar PerKhasa, 2(2), 197-211. Retrieved from http://jurnal. stkippersada.ac.id/jurnal/index.php/JPD P/article/view/112/122

Dike, Daniel, \& Parida, L. 2019. Hexagonal management kelas dalam pemebelajaran di sekolah dasar. Akuntabilitas Management Pendidikan, 7(1), 35-49. https://doi.org/Permalink/DOI: http://dx. doi.org/ 10.21831/amp.v7i1. 23268

Goverment, V. S. 2018. Education and training: shoools, teaching and curiculum, and arts. Retrieved from https://www. education.vic.gov.au/school/teachers/tea chingresources/discipline/arts/Pages/def ault.aspx

Henry Lopolalan. 2014. Cita 9 agenda prioritas jokowi-jk. Kompas.Com. Retrieved from https://nasional.kompas.com/read/2014/ 05/21/0754454/.Nawa.Cita.9.Agenda.Pri oritas.Jokowi-JK

Iman Gunawan. 2015. Metode penelitian kualitatif. Jakarta: PT Bumi Aksara.

John Keedy. 2002. Cultural leadership in school administration. Journal of Thought, 2(3), 3-9.

Lynch, M. 2015. Becoming a transformatonal school leadership. The Tech Advocate.

Majelis Luhur Persatuan Taman Siswa. 2013. Kihadjar Dewantara: Pemikiran, konsepsi, keteladanan, sikap merdeka (II). Yogyakarta: Universitas Sarjanawiyata Tamansiswa (UST Press).

Martell, C. C. 2017. Approaches to teaching race in elementary social studies: A case study of preservice teachers. The Journal of Social Studies Research, 41(1), 75-87. https://doi.org/10.1016/ j.jssr.2016.05.001

Michael Bonnet. 2010. Martin Heidegger. In Joy A. Palmer (Ed.), 50 Pemkir paling berpengaruh terhadap dunia pendidikan moderen: Biografi, dedikasi, dan kontribusinya (Terjemahan, pp. 45-52). Jakarta: Penerbit Laksana. Retrieved from www.divapress_online. com

Miles, Matthew \& Huberman, M. 1994. Qualitative data analysis. Thousand Oaks, CA.: Sage Publications.

Nonoka, I. 2005. Managing organizational knowledge theoretical and methodological foundations, great minds in management: The process of theory and development. London: Oxford, Oxford University Press.

Ozkan, S. 2015. Evaluating learning management systems: Hexagonal e-learning assessment (HELAM). European and Mediterranean Conference on Information Systems, European a (January 2008), 1-17. Retrieved from https://www. researchgate.net/publication/237325850 _Evaluating_learning_management_syst ems_Hexagonal_e-learning_assessment_ model_HELAM

Prayogi. 2019. Kepsek tewas ditusuk orang tua murid di sintang kalbar. Republika. Retrieved from https://nasional. republika.co.id/berita/pzia9a384/kepsektewas-ditusuk-orang-tua-murid-di-sintan g-kalbar 
Pujianto, A. 2019. Terungkap asal sekolah kasus bully siswi sintang, dilakukan siswi lain yang juga kakak kelas korban. Tribun Pontianak. Retrieved from https://pontianak.tribunnews.com/2019/1 0/22/terungkap-asal-sekolah-kasus-bully -siswi-sintang-dilakukan-siswi-lain-yang -juga-kakak-kelas-korban?page $=4$

setiawati, T. \& Nia R. 2018. Pengaruh Biblitheorapy Terhadap Perkembangan Karakter Disiplin Pada Siswa Sekolah Dasar. JIKAP PGSD: Jurnal Ilmiah Ilmu Kependidikan, 2 (2): 142-146

Suyanto. 2014. Pembelajaran karakter di sekolah. Yogyakarta. Retrieved from http://eprints.uny.ac.id/20641/1/PPT-PE

MBELAJARAN KARAKTER LPPM UNY.pptx

Tarsisius Sarkimin. 2017. Sekolah Katolik: Penegasan Misi, penguatan tata kelola dan peningkatan kualitas sumber daya. In Rosalia Emmy (Ed.), Lembaga Pendidikan Katolik (ke 5, pp. 61-89). Yogyakarta: PT Kanisius.

Tim Penyusun. 2017a. Konsep dan pedoman penguatan pendidikan karakter tingkat sekolah dasar dan sekolah menengah pertama. Jakarta: Kemdikbud.

Tim Penyusun. 2017b. Konsep dasar penguatan pendidikan karakter: senang belajar di rumah kedia. Jakarta: Kemdikbud.

Wahidin. 2019a. Terkait persoalan lampion, wabup askiman tegaskan sudah diselesaikan dengan damai. Tribun Pontianak. Retrieved from https://pontianak.tribunnews.com/2019/0 2/05/terkait-persoalan-lampion-wabup-a skiman-tegaskan-sudah-diselesaikan-den gan-damai

Wahidin. 2019b. Sekda yosepha hasnah buka kegiatan pelatihan PRB dan evaluasi program kiat guru kabupaten sintang. Tribun Pontianak, pp. 1-2. Retrieved from

https://pontianak.tribunnews.com/2019/0 7/03/sekda-yosepha-hasnah-buka-kegiat an-pelatihan-prb-dan-evaluasi-programkiat-guru-kabupaten-sintang

Yukl, G. 2002. Leadership in organizations (5th ed.). Upper Saddle River: Prentice-Hall.

Yuningsih, E., \& Herawan, E. 2015. Kepemimpinan transformasional kepala sekolah dan iklim sekolah terhadap sekolah efektif pada sd negeri di purwakarta. Jurnal Administrasi Pendidikan, XXII(2), 81-92.

Zamroni. 2014. Percikan pemikiran pendidikan Muhammadiayah. Yogyakarta: Penerbit Ombak. 